\title{
A dual response surface optimization methodology for achieving uniform coating thickness in powder coating process
}

\author{
Boby John*
}

SQC \& OR Unit, Indian Statistical Unit, Bangalore, India - 560059

\begin{tabular}{l}
\hline C H R O N I C L E \\
\hline Article history: \\
Received May 162014 \\
Received in Revised Format \\
April 102015 \\
Accepted May 202015 \\
Available online \\
May 202015 \\
\hline Keywords: \\
Powder coating \\
Industrial enclosures \\
Dual response surface \\
methodology \\
Design of experiments \\
Analysis of variance
\end{tabular}

\begin{abstract}
A B S T R A C T
The powder coating is an economic, technologically superior and environment friendly painting technique compared with other conventional painting methods. However large variation in coating thickness can reduce the attractiveness of powder coated products. The coating thickness variation can also adversely affect the surface appearance and corrosion resistivity of the product. This can eventually lead to customer dissatisfaction and loss of market share. In this paper, the author discusses a dual response surface optimization methodology to minimize the thickness variation around the target value of powder coated industrial enclosures. The industrial enclosures are cabinets used for mounting the electrical and electronic equipment. The proposed methodology consists of establishing the relationship between the coating thickness \& the powder coating process parameters and developing models for the mean and variance of coating thickness. Then the powder coating process is optimized by minimizing the standard deviation of coating thickness subject to the constraint that the thickness mean would be very close to the target. The study resulted in achieving a coating thickness mean of 80.0199 microns for industrial enclosures, which is very close to the target value of 80 microns. A comparison of the results of the proposed approach with that of existing methodologies showed that the suggested method is equally good or even better than the existing methodologies. The result of the study is also validated with a new batch of industrial enclosures.
\end{abstract}

\section{Introduction}

The industrial enclosures are cabinets used for mounting the electrical and electronic equipment. The enclosures protect the equipment from outside environment and adverse weather conditions. The enclosures can also protect the user from electromagnetic interferences (Chen et al., 2008). In many situations, only the enclosure will be visible to the users. Hence the appearance of the enclosures should be attractive to the customers. The enclosure painting process is a very important step in enclosure manufacturing process. The enclosures are generally painted using powder coating method. The powder coating, as a painting technique, does not require any solvent and is applied as free flowing dry powder. The solvent emission is considered as a major problem in surface coating industry. Hence powder coating has superior techno-economic benefits (Naderi et al., 2004). It creates a hard finish. The first step in 
powder coating is the preparation of the surface to be coated. This involves removal of oil, greases, etc. from the surface. The common methods for surface preparation are degreasing, etching, rinsing, etc. After the surface is prepared, it is heated and the powder is sprayed to the metal surface using an electrostatic gun. The powder melts to form a uniform film and is then cooled or cured to form a hard coating.

The coating thickness is an important quality characteristic of powder coating process. It affects the mechanical and physical properties of the coated surface. If the coating thickness is not uniform across the surface, it would impact the hardness, surface appearance and corrosion resistivity of the enclosures. A company manufacturing industrial enclosures is facing the serious problem of coating thickness variation in the powder coated enclosures. This reduced the attractiveness of the enclosures and also resulted in customer dissatisfaction. Hence this study is undertaken to develop a methodology to reduce the variation in coating thickness around the target for industrial enclosures.

The remaining part of the paper is arranged as follows. The methodology is discussed in session 2 . The data collection and analysis is given in session 3. The session 4 provides the optimization details. The results are discussed in session 5 and validated in session 6. The conclusions are given in session 7.

\section{Methodology}

There are many approaches for achieving the target value of a response variable. Most of these approaches are based on response surface methodology (Box \& Draper, 1987). Response surface methodology (RSM) is a collection of statistical and mathematical techniques for improving and optimizing processes (Mayers et al., 2009). The RSM identifies the best settings for a set of input or design variables that would optimize the response $y$ (Box \& Wilson, 1951; Sahoo et al., 2013). Lots of work, both theoretical and applied, have been carried out in the recent past in the area of response surface methodology (Khuri \& Mukhopadhyay, 2010; Bezerr et al., 2008; Baş \& Boyac1, 2007; Liyana-Pathirana \& Shahidi, 2005; Noordin, 2004; Öktem, 2005; Barton, 2013). The main emphasis of RSM is on optimizing the estimated mean of the response variable (Ding et al., 2004). The mean is estimated using a polynomial model given in Eq. (1).

$$
\hat{y}_{\mu}=a_{0}+\sum_{i=1}^{k} a_{i} x_{i}+\sum_{i=1}^{k} a_{i i} x_{i}^{2}+\sum \sum_{i<j}^{k} a_{i j} x_{i} x_{j}
$$

where $\hat{y}_{\mu}$ is the estimated value of the mean of the response $y$ and $x i, i=1,2, \ldots, k$, are the exploratory variables. Using Eq. (1), the optimum values of $x_{i}$ 's, which would bring $\hat{y}_{\mu}$ close to the target is then determined. But the optimum $x_{i}$ 's may not minimize or change the variance. In RSM and traditional industrial experimentation, it is assumed that the variance is constant. But the assumption on constant variance doesn't hold well in many industrial scenarios. Hence it is required to simultaneously optimize multiple responses, namely mean and variance of the response variable (Taguchi, 1986; Phadke, 1995). The most efficient methodology for simultaneous optimization of the mean and variance is dual response surface methodology (Myers \& Cartel, 1973). In dual RSM, along with the model for estimating the mean of the response variable, another polynomial model for estimating the standard deviation is also developed as shown in Eq. (2).

$$
\hat{y}_{\sigma}=b_{0}+\sum_{i=1}^{k} b_{i} x_{i}+\sum_{i=1}^{k} b_{i i} x_{i}^{2}+\sum \sum_{i<j}^{k} b_{i j} x_{i} x_{j}
$$

where $\hat{y}_{\sigma}$ is the estimated value of the standard deviation of the response $y$ and $x_{i}, i=1,2,-\cdots, k$, are the exploratory variables. Then both the responses (mean and variance) are optimized, simultaneously.

Several methods have been proposed for the simultaneous optimization of mean and variance of the response variable. The important among them are

- Vining and Mayers (VM) method (Vining \& Myers, 1990)

- $\quad$ Lin and Tu (LT) method (Lin \& Tu, 1995)

- $\quad$ Copeland and Nelson (CN) method (Copeland \& Nelson, 1996) 
- Quality loss function (QLP) method (Ames et al., 1997).

In VM method, one of the responses is taken as the primary response and the other one as a constraint. The VM approach is to

$\min \hat{y}_{\sigma}$

subject to $\hat{y}_{\mu}=T$

where $\hat{y}_{\mu}$ and $\hat{y}_{\sigma}$ are estimated mean and standard deviation of the response variable $y$ obtained using Eq. (1) and Eq. (2). $T$ is the target value for $y$. Del Castillo and Montgomery (1993) showed that the VM problem can be solved using Excel solver (Brown, 2001). The Excel solver uses generalized reduced gradient algorithm for solving optimization problems. Still many researchers encountered the problem of not getting a feasible solution to the dual response optimization problem using VM method. This is because the VM method tries to find out an optimum solution which forcefully ensures the mean exactly on target.

The LT method proposes to solve the dual response optimization problem by minimizing the mean square error (MSE). The LT method is to

$$
\min M S E=\left(\hat{y}_{\mu}-T\right)^{2}+\hat{y}_{\sigma}^{2}
$$

where $\hat{y}_{\mu}$ and $\hat{y}_{\sigma}$ are estimated mean and standard deviation of the response variable $y$ obtained using Eq. (1) and Eq. (2). $T$ is the target value for $y$. The problem with LT method is that it may minimize the MSE without bringing $\hat{y}_{\mu}$ close to the target $T$. This is because the LT method does not have an upper limit or restriction on the deviation of $\hat{y}_{\mu}$ from the target $T$.

The aforementioned problem is taken care in $\mathrm{CN}$ method. The $\mathrm{CN}$ method is to

$$
\begin{aligned}
& \min \hat{y}_{\sigma} \\
& \text { subject to }\left(\hat{y}_{\mu}-T\right)^{2} \leq \Delta^{2} \text {, }
\end{aligned}
$$

where $\Delta$ is the maximum allowed deviation of estimated mean $\hat{y}_{\mu}$ from the specified target value. The $\mathrm{CN}$ method is considered to be logically sounder among the aforementioned three methods. But the CN method is also not free from problems. The presence of higher order polynomials in the constraint sometimes makes it difficult to obtain the global optimum solution using commonly used optimization programs like Excel solver.

An alternative approach suggested is to minimize the quality loss function (referred as QLP method). Many papers on a wide variety of applications of Taguchi's loss function is published in the recent past (Liao \& Kao, 2010; Pi \& Low, 2006; Antony, 2000; Antony, 2001; Wu, 2004; Kethley, 2002; Chan \& Ibrahim, 2004; Cho \& Cho, 2008; John, 2012). The QLP method is to

$$
\min Q L P=w_{\mu}\left(\hat{y}_{\mu}-T_{\mu}\right)^{2}+w_{\sigma}\left(\hat{y}_{\sigma}-T_{\sigma}\right)^{2},
$$

where $\hat{y}_{\mu}$ and $\hat{y}_{\sigma}$ are the estimated mean and standard deviation of the response variable, $w_{\mu}$ and $w_{\sigma}$ are the weights assigned to mean and standard deviation of the response and $T_{\mu}$ and $T_{\sigma}$ are the respective target values for mean and standard deviation of the response variable. The problem with QLP method is that the solution would be influenced by the weights $w_{\mu}$ and $w_{\sigma}$. 
In this study, the author has used the $\mathrm{CN}$ method and the problem of higher order polynomials in the constraints is handled by slightly modifying the $\mathrm{CN}$ method. The methodology is a simplified version of the $\mathrm{CN}$ method. The step by step details of the proposed methodology is given below:

1. Identify the control variables or factors $x_{i}$ 's, $i=1,2, \ldots, k$.

2. Identify the important factors among $x_{i}$ 's which significantly influence the response variable through design of experiments.

3. Develop the models for estimating the mean $\hat{y}_{\mu}$ and the standard deviation $\hat{y}_{\sigma}$ of the response variable y.

4. Identify the optimum values of $x_{i}$ 's which would simultaneously optimize the mean and standard deviation of response $y$ by

$\min \hat{y}_{\sigma}$

subject to $(T-\Delta) \leq \hat{y}_{\mu} \leq(T+\Delta)$,

where $\Delta$ is the maximum allowed deviation of estimated mean $\hat{y}_{\mu}$ from the specified target value $T$. The optimization problem (7) can be easily solved using the generalized reduced gradient algorithm of Excel solver (Fylstra et al., 1998).

\section{Data collection and analysis}

Through discussions with the technical personals and surface coating experts of the company four variables namely oven temperature (in ${ }^{0} \mathrm{C}$ ), curing time (in minutes), conductivity (in micro seimens) and powder output (in grams per second) of the powder coating process are identified as factors for the study. The coating thickness (in microns) is chosen as the response variable. The effect of the factors on the coating thickness is studied using design of experiments. The design of experiments is an efficient tool for optimizing the process and product characteristics (Chowdhury \& Boby, 2003; Surm et al., 2005; Wang et al., 2008; Bhuiyan, 2011; Sahoo \& Sahoo, 2011; Boby, 2013; Kirshna et al., 2013; Saha \& Mandal, 2013; Sahoo, 2014). Since response surfaces need to be fitted for mean and variance of the response variable, a central composite design (CCD) is chosen for experimentation (Alam et al., 2008). The central composite designs have less number of experiments compared to 3 level full factorial experiments. The CCDs are factorial experiments augmented with additional central and axial points. The factors with the levels, central points and axial points are given in Table 1.

Table 1

Factors with levels

\begin{tabular}{lcccccc}
\hline \multirow{2}{*}{ Factor Name } & \multirow{2}{*}{ Code } & \multicolumn{2}{c}{ Levels } & Central Point & \multicolumn{2}{c}{ Axial Points } \\
\cline { 2 - 7 } & & -1 & +1 & 0 & -2 & 2 \\
\hline Oven Temperature & $x_{1}$ & 185 & 200 & 192.5 & 177.5 & 207.5 \\
Curing Time & $x_{2}$ & 10 & 12 & 11 & 9 & 13 \\
Conductivity & $x_{3}$ & 1500 & 1800 & 1650 & 1350 & 1950 \\
Powder Output & $x_{4}$ & 32 & 34 & 33 & 31 & 35 \\
\hline
\end{tabular}

The experiments are conducted as per the design and the response, coating thickness is measured. Each experiment is replicated twice. The experimental layout with the mean and variance of the response is given in Table 2 . The mean of the response is subjected to analysis of variance (Box, 2009). The ANOVA table is given in Table 3 .

The ANOVA table showed that the regression is significant ( $\mathrm{p}$ value $=0.00<0.05$ ) at $5 \%$ level. The ANOVA table also revealed that the square terms ( $\mathrm{p}$ value $=0.977>0.05)$ and interaction terms ( $\mathrm{p}$ value $=0.984>0.05$ ) are insignificant. Hence the linear model is adequate. Moreover the lack of fit ( $\mathrm{p}$ value = $0.953>0.05$ ) is insignificant indicating that the linear model is a good fit. The coefficients of the significant factors are given in Table 4. The residual plots are given in Fig. 1. 
Table 2

Experimental layout with response mean and variance

\begin{tabular}{|c|c|c|c|c|c|c|}
\hline \multirow[b]{2}{*}{ Exp No } & \multirow[b]{2}{*}{ Oven Temperature } & \multirow[b]{2}{*}{ Curing Time } & \multirow[b]{2}{*}{ Conductivity } & \multirow[b]{2}{*}{ Powder Output } & \multicolumn{2}{|c|}{ Thickness } \\
\hline & & & & & Mean & Variance \\
\hline 1 & 185 & 10 & 1500 & 32 & 80.5 & 12.5 \\
\hline 2 & 200 & 10 & 1500 & 32 & 81.5 & 12.5 \\
\hline 3 & 185 & 12 & 1500 & 32 & 79.5 & 4.5 \\
\hline 4 & 200 & 12 & 1500 & 32 & 81 & 8.00002 \\
\hline 5 & 185 & 10 & 1800 & 32 & 89 & 8.00002 \\
\hline 6 & 200 & 10 & 1800 & 32 & 90.5 & 12.5 \\
\hline 7 & 185 & 12 & 1800 & 32 & 88 & 8.00002 \\
\hline 8 & 200 & 12 & 1800 & 32 & 89 & 8.00002 \\
\hline 9 & 185 & 10 & 1500 & 34 & 107 & 8.00002 \\
\hline 10 & 200 & 10 & 1500 & 34 & 108.5 & 12.5 \\
\hline 11 & 185 & 12 & 1500 & 34 & 106 & 8.00002 \\
\hline 12 & 200 & 12 & 1500 & 34 & 107.5 & 12.5 \\
\hline 13 & 185 & 10 & 1800 & 34 & 116 & 8.00002 \\
\hline 14 & 200 & 10 & 1800 & 34 & 117 & 8.00002 \\
\hline 15 & 185 & 12 & 1800 & 34 & 115 & 8.00002 \\
\hline 16 & 200 & 12 & 1800 & 34 & 116.5 & 4.5 \\
\hline 17 & 177.5 & 11 & 1650 & 33 & 96.5 & 4.5 \\
\hline 18 & 207.5 & 11 & 1650 & 33 & 99.5 & 12.5 \\
\hline 19 & 192.5 & 9 & 1650 & 33 & 99.5 & 12.5 \\
\hline 20 & 192.5 & 13 & 1650 & 33 & 97 & 1.99999 \\
\hline 21 & 192.5 & 11 & 1350 & 33 & 90 & 8.00002 \\
\hline 22 & 192.5 & 11 & 1950 & 33 & 106.5 & 4.5 \\
\hline 23 & 192.5 & 11 & 1650 & 31 & 72 & 8.00002 \\
\hline 24 & 192.5 & 11 & 1650 & 35 & 124.5 & 4.5 \\
\hline 25 & 192.5 & 11 & 1650 & 33 & 98.5 & 4.5 \\
\hline 26 & 192.5 & 11 & 1650 & 33 & 97.5 & 4.5 \\
\hline 27 & 192.5 & 11 & 1650 & 33 & 98.5 & 4.5 \\
\hline 28 & 192.5 & 11 & 1650 & 33 & 97.5 & 4.5 \\
\hline 29 & 192.5 & 11 & 1650 & 33 & 99 & 8.00002 \\
\hline 30 & 192.5 & 11 & 1650 & 33 & 98 & 8.00002 \\
\hline 31 & 192.5 & 11 & 1650 & 33 & 99 & 8.00002 \\
\hline
\end{tabular}

Table 3

ANOVA table for thickness mean

\begin{tabular}{|c|c|c|c|c|c|}
\hline Source & $\mathrm{DF}$ & SS & MS & $\mathrm{F}$ & $\mathrm{p}$ \\
\hline Regression & 14 & 4709.28 & 336.38 & 1471.41 & 0.00 \\
\hline Linear & 4 & 4708.96 & 1177.24 & 5149.59 & 0.00 \\
\hline Square & 4 & 0.1 & 0.03 & 0.11 & 0.977 \\
\hline Interaction & 6 & 0.22 & 0.04 & 0.16 & 0.984 \\
\hline Residual Error & 16 & 3.66 & 0.23 & & \\
\hline Lack-of-Fit & 10 & 1.23 & 0.12 & 0.3 & 0.953 \\
\hline Pure Error & 6 & 2.43 & 0.4 & & \\
\hline Total & 30 & 4712.94 & & & \\
\hline
\end{tabular}

Table 4

Coefficient table for thickness mean

\begin{tabular}{lccccc}
\hline & Code & Coefficients & Standard Error & t Stat & P-value \\
\hline Intercept & & -399.950269 & 3.561889813 & -112.29 & 0 \\
Oven Temp & $x_{1}$ & 0.091666667 & 0.010644676 & 8.6115 & 0 \\
Curing Time & $x_{2}$ & -0.52083333 & 0.079835072 & -6.5239 & 0 \\
Conductivity & $x_{3}$ & 0.028472222 & 0.000532234 & 53.4957 & 0 \\
Powder Output & $x_{4}$ & 13.3125 & 0.079835072 & 166.75 & 0 \\
\hline
\end{tabular}




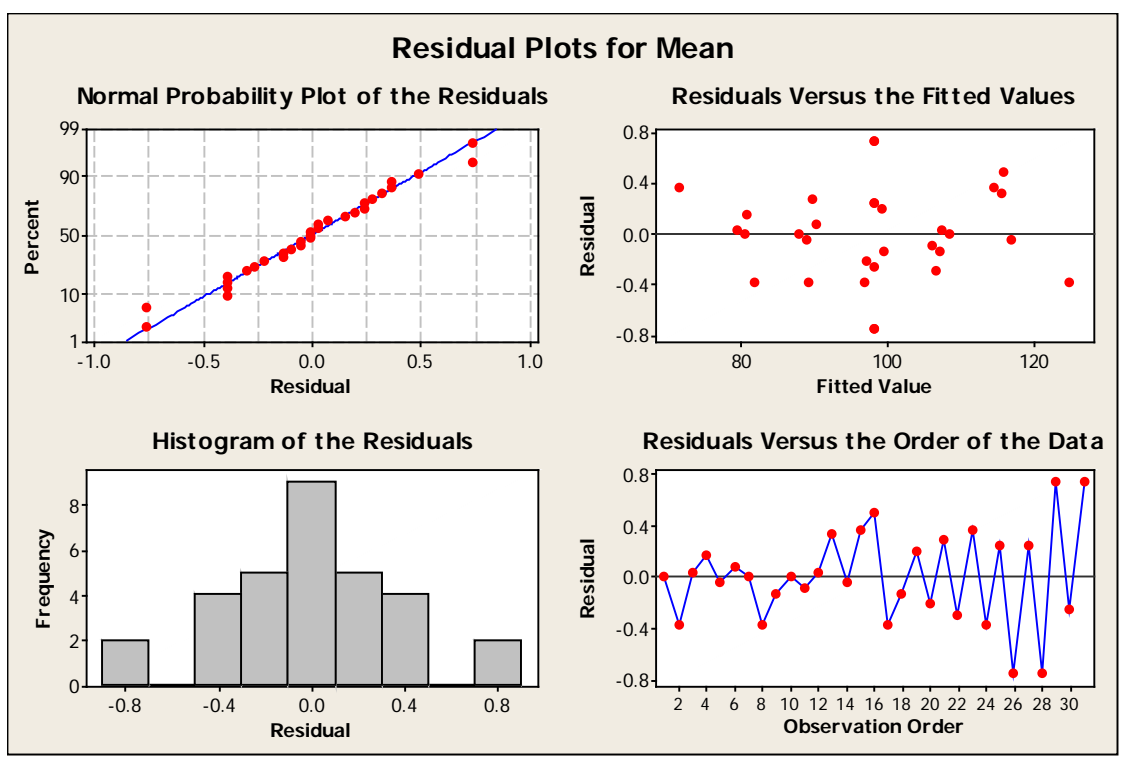

Fig. 1. Residual plots for thickness mean

The residual plot showed that the residuals are approximately normally distributed and there is no trend or pattern in the residual versus order of the data or residual versus the fitted values (Montgomery, 2012). Hence the model for the mean of the coating thickness is identified as

$$
\widehat{y}_{\mu}=-399.950269+0.0916667 x_{1}-0.52083333 x_{2}+0.028472222 x_{3}+13.3125 x_{4}
$$

Similarly the variance of the response is subjected to analysis of variance. The ANOVA table for variance is given in Table 5.

\section{Table 5}

ANOVA table for thickness variance

\begin{tabular}{cccccc}
\hline Source & DF & SS & MS & F & P \\
\hline Regression & 14 & 198.23 & 14.159 & 2.56 & 0.037 \\
Linear & 4 & 131.04 & 32.76 & 5.92 & 0.004 \\
Square & 4 & 36.35 & 9.087 & 1.64 & 0.213 \\
Interaction & 6 & 30.84 & 5.141 & 0.93 & 0.501 \\
\hline Residual Error & & 16 & 88.6 & 5.538 & \\
$\quad$ Lack-of-Fit & 10 & 67.6 & 6.76 & 1.93 & 0.217 \\
$\quad$ Pure Error & & 6 & 21 & 3.5 & \\
\hline Total & 30 & 286.84 & & & \\
\hline
\end{tabular}

The ANOVA table shows the regression is significant ( $\mathrm{p}$ value $=0.037<0.05$ ) at $5 \%$ level and the lack of fit ( $\mathrm{p}$ value $=0.2176>0.05$ ) is insignificant indicating that the regression model is a good fit. The coefficients of the significant factors are given in Table 6.

\section{Table 6}

Coefficient table for thickness variance

\begin{tabular}{lccccc}
\hline & Code & Coefficients & Standard Error & t Stat & P-value \\
\hline Intercept & & 535.3152619 & 294.7195892 & 1.81635 & 0.08044 \\
Oven Temperature & $x_{1}$ & -5.45348197 & 3.06295487 & -1.7805 & 0.08626 \\
Curing Time & $x_{2}$ & -1.7291612 & 0.495350216 & -3.4908 & 0.00167 \\
\hline Oven Temperature $^{2}$ & $x_{1}{ }^{2}$ & 0.014590571 & 0.007953877 & 1.8344 & 0.07764 \\
\hline
\end{tabular}


Table 6 revealed that the factor namely curing time $\left(x_{2}\right)$ is significant at $5 \%$ level and the oven temperature $\left(x_{1}\right)$ and over temperature ${ }^{2}\left(x_{1}{ }^{2}\right)$ are significant at $10 \%$ level (p value $<0.10$ ). The residual plots are given in Fig. 2.

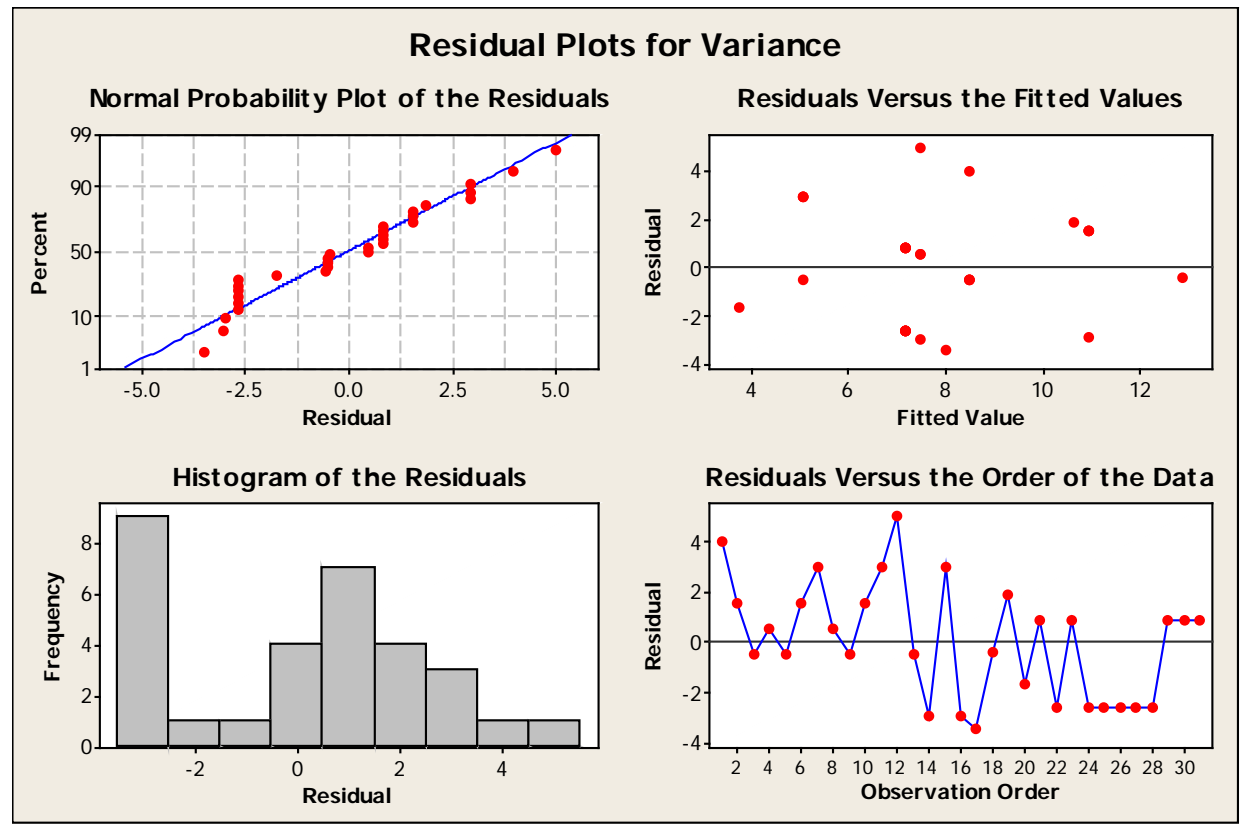

Fig. 2. Residual plots for thickness variance

The residual plot showed that the residuals are normally distributed and there is no trend or pattern in the residual versus order of the data or residual versus the fitted values. Hence the model for the variance of coating thickness is identified as

$$
\hat{y}_{\sigma}^{2}=535.315262-5.4534821 x_{1}-1.729161 x_{2}+0.014591 x_{1}^{2}
$$

\section{Optimization}

The company professionals suggested that a coating thickness of 80 microns is ideal for the industrial enclosures. Hence the thickness target is chosen as 80 with a tolerance $\Delta$ of 0.05 microns. Substituting Eq. (8) and Eq. (9) in Eq. (7), the optimization problem became

$$
\min \hat{y}_{\sigma}=\left(535.315262-5.4534821 x_{1}-1.729161 x_{2}+0.014591 x_{1}^{2}\right)^{0.5}
$$

subject to

$$
\begin{aligned}
& 79.95 \leq-399.950269+0.0916667 x_{1}-0.52083333 x_{2}+0.028472222 x_{3}+13.3125 x_{4} \leq 80 \\
& 185 \leq x_{1} \leq 200 \\
& 10 \leq x_{2} \leq 12 \\
& 1500 \leq x_{3} \leq 1800 \\
& 32 \leq x_{4} \leq 34 \\
& x_{i}, i=1, . ., 4 \text { integer }
\end{aligned}
$$


The integer constraint is added because the least count for most of the factors is one unit. The aforementioned problem is an integer programming problem (Hiller and Liberman, 2008; Taha, 2007). This problem can be solved using Excel solver. The solver uses one of the most robust nonlinear programming methods, namely generalized reduced gradient algorithm. This algorithm is developed by Lasdon and Waren (Lasdon \& Waren, 1977; Lasdon et al., 1978). Moreover lot of studies have been published on the applications of MS Excel solver in solving industrial problems (Souliman et al., 2010; Dasgupta, 2008; Fang, 2006; Brown, 2006). The solution obtained is given in Table 7. The table showed that the optimum combination of factors would give an average coating thickness of 80.0199 microns, very close to the target value of 80 microns with a standard deviation of 2.232 microns.

\section{Table 7}

Optimum solution

\begin{tabular}{lcc}
\hline Factors & Code & Optimum value \\
\hline Oven Temperature & $\mathrm{x}_{1}$ & 187 \\
Curing Time & $\mathrm{X}_{2}$ & 12 \\
Conductivity & $\mathrm{X}_{3}$ & 1513 \\
Powder Output & $\mathrm{X}_{4}$ & 32 \\
Mean & & 80.0199 \\
Standard Deviation & & 2.23201 \\
\hline
\end{tabular}

\section{Results and discussion}

In this study, models are developed for estimating the mean and variance of the coating thickness of powder coated enclosures. The models are developed in terms of powder coating process parameters namely oven temperature, curing time, conductivity and powder output. Then the variation around the target value of coating thickness is minimized by simultaneously optimizing the mean and standard deviation of the coating thickness. The study showed that the optimum values of oven temperature, curing time, conductivity and powder output would give an estimated average coating thickness of 80.0199 microns, very close to the target value of 80 microns.

\section{Table 8}

Comparison of results obtained using different optimization methods

\begin{tabular}{lccccccc}
\hline Factors & Code & Proposed Method & VM Method & LT Method & CN Method & QLP Method \\
\hline Oven Temperature & $\mathrm{x}_{1}$ & 187 & & 187 & 187 & 187 \\
Curing Time & $\mathrm{x}_{2}$ & 12 & No feasible & 1513 & 12 & 12 \\
Conductivity & $\mathrm{X}_{3}$ & 1513 & Solution & 32 & 32 & 1513 \\
Powder Output & $\mathrm{x}_{4}$ & 32 & & 80.0199 & 79.7921 & 80.0199 \\
Mean & & 80.0199 & & 2.23201 & 2.23201 & 2.23201 \\
SD & & 2.23201 & & & & 12 \\
\hline
\end{tabular}

The results obtained through the proposed methodology are compared with the existing methodologies for simultaneous optimization of the mean and standard deviation of response variable. The comparison result is given in Table 8. The Table shows that the VM method does not give any feasible solution. This is because VM method forces the estimated mean to be exactly equal to the target value. The LT and QLP methods give the same optimum combination. The CN method gives a different optimum combination with estimated mean equal to 79.7921 microns not as good as other methods. But all the methods except VM method minimized the estimated standard deviation to 2.23201 microns. Hence it is concluded that the proposed methodology is equally good for simultaneously optimizing the mean and standard deviation of a response variable. Moreover the optimum problem can be easily solved through the MS Excel solver function.

\section{Validation}

The results are presented to the management of the company and it is decided to validate the results by powder coating a pilot batch of 12 enclosures with optimum settings. The results of the validation study 
are given in Table 9. The table shows that the mean of the coating thickness for the pilot batch is 80 microns, very close to the estimated mean of 80.0198 and the standard deviation is 2.1742 microns, again very close to the estimated standard deviation of 2.2302 microns. The results of validation study are submitted to the management and it is decided to implement the optimum solution for powder coating all future enclosures.

\section{Table 9}

Validation of results

\begin{tabular}{lcccccccccccc}
\hline Enclosure No. & 1 & 2 & 3 & 4 & 5 & 6 & 7 & 8 & 9 & 10 & 11 & 12 \\
\hline Thickness & 84 & 83 & 80 & 78 & 79 & 82 & 80 & 79 & 80 & 80 & 76 & 79 \\
\hline
\end{tabular}

Mean $=80$ Standard deviation 2.1742 Variance $=4.7273$

\section{Conclusion}

This paper presented a methodology for reducing the variation in coating thickness around the target value of powder coated industrial enclosures. The methodology is based on dual response surface optimization technique. Four powder coating process variables namely oven temperature, curing time, conductivity and powder output are selected as factors and the coating thickness is chosen as the response for the study. A 31 run central composite design is used for the study. Based on experimental results, polynomial models are developed for estimating the mean and variance of the coating thickness. The powder coating process is then optimized by minimizing the estimated standard deviation of the coating thickness subject to the constraint that the estimated mean of coating thickness would be very close to the target. The aforementioned integer programming problem is solved using Excel solver. The study showed that the optimum combination would yield a mean coating thickness of 80.0199 microns which is very close to the target value of 80 microns. The study also reduced the estimated standard deviation of coating thickness to 2.2301 microns. The solution obtained using the proposed method is compared with that of existing dual response surface optimization methodologies. It is found that the proposed method is equally good or even better than many of the existing methodologies.

The findings of the study are presented to the management of the company. As per the directions of the management, the results of the study are once again validated by powder coating a new batch of twelve enclosures with the optimum combination of factors. This pilot study confirmed the results. Hence it is decided to use the optimum combination of the factors for powder coating all the future enclosures. The same approach can be used for optimizing similar surface coating processes.

\section{References}

Alam, M. Z., Jamal, P., \& Nadzir, M. M. (2008). Bioconversion of palm oil mill effluent for citric acid production: statistical optimization of fermentation media and time by central composite design. World Journal of Microbiology and Biotechnology, 24(7), 1177-1185.

Ames, A. E., Mattucci, N., Macdonald, S., Szonyi, G., \& Hawkins, D. M. (1997). Quality loss functions for optimization across multiple response surfaces. Journal of Quality Technology, 29(3), 339-346.

Antony, J. (2000). Multi-response optimization in industrial experiments using Taguchi's quality loss function and principal component analysis. Quality and reliability engineering international, 16(1), 3-8.

Antony, J. (2001). Simultaneous optimization of multiple quality characteristics in manufacturing processes using Taguchi's quality loss function. The International Journal of Advanced Manufacturing Technology, 17(2), 134-138.

Barton, R. R. (2013). Response surface methodology. In Encyclopedia of Operations Research and Management Science, 1307-1313. Springer US.

Bashiri, M., \& Moslemi, A. (2013). Simultaneous robust estimation of multi-response surfaces in the presence of outliers. Journal of Industrial Engineering International, 9(1), 1-12. 
Baş, D., \& Boyac1, İ. H. (2007). Modeling and optimization I: Usability of response surface methodology. Journal of Food Engineering, 78(3), 836-845.

Bezerra, M. A., Santelli, R. E., Oliveira, E. P., Villar, L. S., \& Escaleira, L. A. (2008). Response surface methodology (RSM) as a tool for optimization in analytical chemistry. Talanta, 76(5), 965-977.

Bhuiyan, N., Gouw, G., \& Yazdi, D. (2011). Scheduling of a computer integrated manufacturing system: A simulation study. Journal of Industrial Engineering and Management, 4(4), 577-609.

Box, G. E., \& Draper, N. R. (1987). Empirical model-building and response surfaces. John Wiley \& Sons.

Box, G. E., \& Wilson, K. B. (1951). On the experimental attainment of optimum conditions. Journal of the Royal Statistical Society. Series B (Methodological), 13(1), 1-45.

Box, G.E. (2009). Statistics for Experiments: Design, Innovation and Discovery. Wiley Series in Probability and Statistics.

Brown, A.M. (2001). A step-by-step guide to non-linear regression analysis of experimental data using a Microsoft Excel spreadsheet. Computer Methods and Programs in Biomedicine, 65, 191 - 200.

Brown, A. M. (2006). A non-linear regression analysis program for describing electrophysiological data with multiple functions using Microsoft Excel. Computer Methods and Programs in Biomedicine, 82(1), 51-57.

Chan, W. M., \& Ibrahim, R. N. (2004). Evaluating the quality level of a product with multiple quality characterisitcs. The International Journal of Advanced Manufacturing Technology, 24(9-10), 738742.

Cho, Y. G., \& Cho, K. T. (2008). A loss function approach to group preference aggregation in the AHP. Computers \& Operations Research, 35(3), 884-892.

Chowdhury, K.K., John, Boby. (2003). Optimization of induction hardening operation using robust design. Journal of Quality Engineering Forum, 11, 70 - 76.

Copeland, K. A., \& Nelson, P. R. (1996). Dual response optimization via direct function minimization. Journal of Quality Technology, 28(3), 331-336.

Dasgupta, P. K. (2008). Chromatographic peak resolution using Microsoft Excel Solver: The merit of time shifting input arrays. Journal of Chromatography A, 1213(1), 50-55.

Del Castillo, E., \& Montgomery, D. (1993). A nonlinear programming solution to the dual response problem. Journal of Quality Technology, 25(3), 199 - 204.

Ding, R., Lin, D. K., \& Wei, D. (2004). Dual-response surface optimization: a weighted MSE approach. Quality Engineering, 16(3), 377-385.

Fang, X., Jiang, S. D., Raut, K., \& Qiu, J. W. (2006). Applications of Microsoft Excel Solver function in water resource engineering. Proceedings of the Texas ASCE Spring Conference, Beaumont, Texas, 19-22.

Fylstra, D., Lasdon, L., Watson, J., \& Waren, A. (1998). Design and use of the Microsoft Excel Solver. Interfaces, 28(5), 29-55.

John, Boby. (2013). Application of desirability function for optimizing the performance characteristics of carbonitrided bushes. International Journal of Industrial Engineering Computations, 4(1), 305315.

John, Boby. (2012). Simultaneous optimization of multiple performance characteristics of carbonitrided pellets: a case study. The International Journal of Advanced Manufacturing Technology, 61(5-8), 585594.

Kethley, R. B., Waller, B. D., \& Festervand, T. A. (2002). Improving customer service in the real estate industry: a property selection model using Taguchi loss functions. Total Quality Management, 13(6), 739-748.

Khuri, A. I., \& Mukhopadhyay, S. (2010). Response surface methodology. Wiley Interdisciplinary Reviews: Computational Statistics, 2(2), 128-149.

Krishna, P., Ramanaiah, N., \& Roa, K. (2013). Optimization of process parameters for friction Stir welding of dissimilar Aluminum alloys (AA2024-T6 and AA6351-T6) by using Taguchi method. International Journal of Industrial Engineering Computations, 4(1), 71-80. 
Lasdon, L. S., Waren, A. D., Jain, A., \& Ratner, M. (1978). Design and testing of a generalized reduced gradient code for nonlinear programming. ACM Transactions on Mathematical Software (TOMS), 4(1), 34-50.

Lasdon, L. S., \& Waren, A. D. (1977). Generalized reduced gradient software for linearly and nonlinearly constrained problems. Graduate School of Business, University of Texas at Austin.

Liao, C. N., \& Kao, H. P. (2010). Supplier selection model using Taguchi loss function, analytical hierarchy process and multi-choice goal programming. Computers \& Industrial Engineering, 58(4), 571-577.

Li, Y., Chen, C., Zhang, S., Ni, Y., \& Huang, J. (2008). Electrical conductivity and electromagnetic interference shielding characteristics of multiwalled carbon nanotube filled polyacrylate composite films. Applied Surface Science, 254(18), 5766-5771.

Liberman, G., \& Hiller, F.S. (2008). Introduction to Operations Research - Concepts and Cases. Tata McGraw Hill Publishing Company Ltd, India.

Lin, D. K., \& Tu, W. (1995). Dual response surface optimization. Journal of Quality Technology, 27(1), 34-39.

Liyana-Pathirana, C., \& Shahidi, F. (2005). Optimization of extraction of phenolic compounds from wheat using response surface methodology. Food chemistry, 93(1), 47-56.

Myers, R. H., \& Anderson-Cook, C. M. (2009). Response surface methodology: process and product optimization using designed experiments. John Wiley \& Sons.

Montgomery, D. C. (2012). Design and Analysis of Experiments. John Wiley \& Sons.

Myers, R. H., \& Carter, W. H. (1973). Response surface techniques for dual response systems. Technometrics, 15(2), 301-317.

Naderi, R., Attar, M. M., \& Moayed, M. H. (2004). EIS examination of mill scale on mild steel with polyester-epoxy powder coating. Progress in Organic Coatings, 50(3), 162-165.

Noordin, M. Y., Venkatesh, V. C., Sharif, S., Elting, S., \& Abdullah, A. (2004). Application of response surface methodology in describing the performance of coated carbide tools when turning AISI 1045 steel. Journal of Materials Processing Technology, 145(1), 46-58.

Öktem, H., Erzurumlu, T., \& Kurtaran, H. (2005). Application of response surface methodology in the optimization of cutting conditions for surface roughness. Journal of Materials Processing Technology, 170(1), 11-16.

Phadke, M. S. (1995). Quality engineering using robust design. Prentice Hall PTR.

Pi, W. N., \& Low, C. (2006). Supplier evaluation and selection via Taguchi loss functions and an AHP. The International Journal of Advanced Manufacturing Technology, 27(5-6), 625-630.

Saha, A., \& Mandal, N. (2013). Optimization of machining parameters of turning operations based on multi performance criteria. International Journal of Industrial Engineering Computations, 4(1), 5160.

Sahoo, A. (2014). Application of Taguchi and regression analysis on surface roughness in machining hardened AISI D2 steel. International Journal of Industrial Engineering Computations, 5(2), 295304.

Sahoo, A., Orra, K \& Routra, B. (2013). Application of response surface methodology on investigating flank wear in machining hardened steel using PVD TiN coated mixed ceramic insert. International Journal of Industrial Engineering Computations, 4(4), 469-478.

Sahoo, A \& Sahoo, B. (2011). Surface roughness model and parametric optimization in finish turning using coated carbide insert: Response surface methodology and Taguchi approach. International Journal of Industrial Engineering Computations, 2(4), 819-830.

Souliman, M. I., Mamlouk, M. S., El-Basyouny, M. M., \& Zapata, C. E. (2010). Calibration of the AASHTO MEPDG for flexible pavement for arizona conditions. Proceedings of the Transportation Research Board 89th Annual Meeting, Washington DC, No. 10-1817.

Surm, H., Kessler, O., Hoffmann, F., \& Mayr, P. (2005). Effect of machining and heating parameters on distortion of AISI 53100 steel bearing rings. International Journal of Materials and Product Technology 24, $270-281$. 
Taguchi, G. (1986). Introduction to quality engineering: designing quality into products and processes. Kraus International Publications, USA.

Taha, H. A. (2007). Operations research: an introduction. Pearson/Prentice Hall.

Vining, G. G., \& Myers, R. H. (1990). Combining Taguchi and response surface philosophies: a dual response approach. Journal of Quality Technology, 22(1), 38 - 45.

Wang, X. Y., Wang, J., Xu, W. J., \& Wu, D. J. (2008). A study of laser surface modification for GCr15 steel. International Journal of Materials and Product Technology, 31(1), 88-96.

Wu, Z., Shamsuzzaman, M., \& Pan, E. S. (2004). Optimization design of control charts based on Taguchi's loss function and random process shifts. International Journal of Production Research, 42(2), 379-390. 